\title{
Validating the Classification of Smallholder Dairy Farming Systems Based on Herd Genetic Structure and Access to Breeding Services
}

\author{
Solomon Gizaw ${ }^{1}$, Megersa Abera ${ }^{2}$, Melku Muluye ${ }^{3}$, Mohammed Aliy ${ }^{4}$, Kefyalew Alemayehu ${ }^{5}$, \\ Azage Tegegne ${ }^{1}$
}

\author{
${ }^{1}$ International Livestock Research Institute, Addis Ababa, Ethiopia \\ ${ }^{2}$ EjereWoreda Livestock and Fisheries Resource Development Office, Addis Alem, Ethiopia \\ ${ }^{3}$ West Gojam Livestock and Fisheries Resource Development Office, Debre Marokos, Ethiopia \\ ${ }^{4}$ Jimma University College of Agriculture and Veterinary Medicine, Jimma, Ethiopia \\ ${ }^{5}$ Bahir Dar University, Bahir Dar, Ethiopia \\ Email: s_gizaw@yahoo.com
}

How to cite this paper: Gizaw, S., Abera, M., Muluye, M., Aliy, M., Alemayehu, K. and Tegegne, A. (2017) Validating the Classification of Smallholder Dairy Farming Systems Based on Herd Genetic Structure and Access to Breeding Services. Agricultural Sciences, 8, 545-558. https://doi.org/10.4236/as.2017.87041

Received: May 12, 2017

Accepted: July 1, 2017

Published: July 4, 2017

Copyright $\odot 2017$ by authors and Scientific Research Publishing Inc. This work is licensed under the Creative Commons Attribution International License (CC BY 4.0).

http://creativecommons.org/licenses/by/4.0/

(c) (i) Open Access

\begin{abstract}
Smallholder dairy farming in Africa is classified into rural, peri-urban and urban systems. The major classification criterion is demographic. Dairy systems are extensively characterized, but not based on rigorous statistical analyses. We validated this classification based on herd genetic structure and identify determinants of within-system variations, taking Ethiopia as a case study. Discriminant function analysis correctly classified $38 \%-50.6 \%$ of the 360 sampled farms into the three systems. Multinomial logistic regression analysis showed that rural and peri-urban farmers were $1.26(\mathrm{P}<0.1)$ to 1.45 $(\mathrm{P}<0.001)$ times more likely to keep local and low grade crossbreds and fewer high grade crosses $(\mathrm{P}<0.05$; odds ratio $=2.35)$ than the urban farmers. In the rural system, proportion of high grade crosses declined and low grades increased over generations, whereas in urban system the reverse was observed. Access to breeding services and land resources significantly determined the adoption of crossbred dairy herd within systems. In conclusion, considering farms within systems as a uniform unit to target development interventions may not be appropriate and thus farm topologies and system specific determinants of farmers' breeding strategies need to be considered to design and introduce appropriate breeding interventions.
\end{abstract}

\section{Keywords}

Smallholder, Dairy Farming Systems, Crossbreeding, Herd Genetic Structure, Breeding Services 


\section{Introduction}

Smallholder dairy farming systems in the highlands of Ethiopia [1] [2] [3] [4] and elsewhere in East Africa [5] [6] [7] are classified as rural, peri-urban and urban systems. The major classification criterion is demographic; the peri-urban and urban systems are located around and in towns and cities. The purpose of classification of farming systems is to develop strategies and interventions relevant to the various systems which may vary in the types and degrees of severity of constraints, resource bases and enterprise patterns. Blanket recommendations of technologies and improved management practices could be one of the reasons for low adoption of interventions by agricultural systems which are highly diverse in agro-ecological and socio-economic conditions.

Dairy farming systems in Ethiopia have been extensively characterized. Since dairy cattle genetic improvement strategies in Ethiopia [8] target the peri-urban/ urban system and the major milksheds for introduction of exotic crossbred dairy cattle, the major distinguishing characteristics of the three highland systems is the herd genetic structure, the urban and peri-urban systems are characterized as crossbred-based systems keeping high grade exotic (mainly Holstein Friesian breed) crossbred cows whereas the rural or traditional system is a local cattle-based system [2] [4] [9]. The studies cited above have however focused on the systems in and around the big cities and the major milksheds. On the other hand, studies on regional towns [3] have indicated that the crossbred herd composition in the urban/peri-urban system is less than reported in the above cited studies. Despite the extensive characterization of dairy farming systems, a comprehensive characterization of dairy systems in the highlands across the value chain supported with valid statistical analyses is not available in the literature. Secondly, the topology of farms within systems and the underlying determinants for within-system variation/diversity in herd genetic composition are not known to confirm if farms within systems could be considered as a uniform unit to target development interventions. In this study, we analyzed farms sampled form of two states in the wet highlands of Ethiopia to validate the classification of the smallholder dairy farming systems, establish the genetic structure of the three systems and identify within-system determinants of variations in herd genetic structure based on a series of statistical analyses taking the smallholder system in Ethiopia as a case study.

\section{Materials and Methods}

\subsection{Sampling Strategy}

This study was conducted in Oromia and Amhara states in Ethiopia. One zone from each of Oromia (West Shoa zone, located at $08^{\circ} 94^{\prime} 09^{\prime} 00.00^{\prime \prime} \mathrm{N}$ $38^{\circ} 005^{\prime} 00.00^{\prime \prime} \mathrm{E}$ ) and Amhara (West Gojam zone, located at $11^{\circ} 09^{\prime} 60.00^{\prime \prime} \mathrm{N}$ $37^{\circ} 14^{\prime} 60.00 " \mathrm{E}$ ) states, and two districts from West Shoa zone (Adaberga and Ejere districts) and three districts from West Gojam zone (Mecha, Bahir Dar Zuria and Ylmana Densa districts) were selected for the study. In each district, 
three Kebeles (the smallest administration unit in Ethiopia) representing the rural, peri-urban and urban production systems were selected based on their geographic/demographic locations. Urban centers selected were Merawi and Adet towns in West Gojam and Ejere and Hinchini towns in West Shoa. A total of 360 farmers from West Gojam (80 from rural area, 60 from peri-urban area and 40 from Merawi and Adet towns) and West Shoa (59 from rural, 61 from peri-urban and 60 from urban production systems) were selected for interviewing.

The agro-ecology of the study sites is wet highlands which are targeted for introduction of crossbred cattle. Adaberga district has altitude ranges of 1166 to 3238 m.a.s, receives an average annual rainfall ranging from 887 to $1194 \mathrm{~mm}$ and the minimum and maximum daily temperatures of the area are 11 and $21^{\circ} \mathrm{C}$, respectively. The corresponding figures for Ejere district are 2631 to 3238 meters, 1107 to $1194 \mathrm{~mm}$ and 11 and $14^{\circ} \mathrm{C}$. The altitudes, rainfall and minimum and maximum daily temperatures for Mecha, Bahir Dar Zuria and Ylmana Densa districts are, respectively, 1800 - 2500, 1700 - 2300 and 1552 to 3535 m.a.s; 820 to $1250 \mathrm{~mm}, 820$ to $1250 \mathrm{~mm}$ and $1270 \mathrm{~mm} ; 17$ and $30^{\circ} \mathrm{C}, 10$ and $32^{\circ} \mathrm{C}$ (temperature data for Yilmana Densa was not available).

\subsection{Data Collection and Analysis}

Questionnaire survey on herd genetic composition, herd size, production resources, and household characteristics based on farmers' recall were collected from February to September 2015 using structured questionnaires. The data from West Shoa and West Gojam zones were analyzed separately to serve as a replication of the study. The genotypes of animals were classified as local, low grade, medium grade and high grade crossbreds based on the exotic blood level of the animals. Low grades were defined as those having about $25 \%$ exotic blood resulting from first cross cows backcrossed to local breed sire, medium grade crosses were first crosses with 50\% exotic blood resulting from crossing of local cows and exotic bulls (usually through AI, artificial insemination), and high grades were animals with about $75 \%$ or above exotic blood resulting from first cross cows crossed with pure exotic sire commonly through AI. The level of exotic blood level for cows supplied by government ranches and research institutes was established from the cow certificate provided by the institute. For animals that were born on the farm, exotic blood levels were estimated from the dam and sire breed type as recalled by the owner and from records of AI service providers.

Discriminant function analysis was used to reclassify the 180 farms in each zone into their original rural, peri-urban and urban categories. A predictive model for assigning the sample farms into the three dairy farming systems was built. The model was composed of discriminant functions based on linear combinations of four predictor variables which represented the genetic compositions of herds. The predictor variables were local, low grade, medium grade and high grade crossbred animals (cows, heifers and calves) in the herds. The variables 
that provided the best discrimination between the groups were selected based on their statistical significance. The classifications were cross-validated applying leave-one-out analysis where each farm was classified by the functions derived from all farms other than the farm to be reclassified. Multinomial logistic regressions were conducted to estimate the probability of keeping the various genotypes across the three farming systems. Factors that would determine adoption of the various genotypes by farmers in the three farming systems were identified through generalized linear regression analysis fitting Poisson distribution with $\log$ transformation of the number of animals as a dependent variable. All analyses were conducted using SPPS version 20 (2011).

\section{Results}

\subsection{Validating the Classification of Farms}

Using discriminant function analyses based on herd genetic structures (number of local, low grade, medium grade and high grade crossbred animals which consisted of cows, heifers and calves) as predictor variables, 180 farms in each of West Shoa and West Gojam zones were reclassified into rural, peri-urban and urban systems (Table 1). The predictor variables that contributed significantly to the reclassification were number of local, low grade, medium grade and high grade crossbred animals in the herds in West Shoa, and number of local and high grade crossbred animals in West Gojam. In West Shoa, the classification function coefficients for number of local animals were marginally higher for the rural and peri-urban system than for the urban system, the coefficients for the number of low grade crossbreds was higher for the rural system than for the peri-urban and urban systems, whereas the coefficients for the high grades for the rural system were lower than for the peri-urban and urban systems. In West Gojam, the coefficients for both local and high grade crossbreds were higher for the urban system than for the rural and peri-urban systems.

The analysis model correctly classified $50.6 \%$ and $38.7 \%$ of the 180 sampled farms in each of West Shoa and West Gojam zones, respectively, into rural, periurban and urban dairy farming systems. The percentage of farms that were correctly classified into their original rural, peri-urban and urban systems were respectively $49.2 \%, 52.5 \%$ and $50.0 \%$ in West Shoa and $43.2 \%, 25.0 \%$ and $50.0 \%$ in West Gojam (Table 2). The highest misclassification was observed in the peri-urban system where $51.7 \%$ of the farms were classified into the rural system in West Gojam, and $45.7 \%$ of the farms were classified into urban system in West Shoa. The improvement in accuracy of classification of the farms using cross-validation method, where classification was done by classifying each farm by the discriminant functions derived from all farms other than the farm to be cross-validated, was not significant. When cross-validation was employed, $0.0 \%$ to $9.9 \%$ of the originally classified farmers were reclassified into a different system (Table 2). 
Table 1. Significant predictor variables (and their classification function coefficients) identified based on significance of their Wilks' Lambda statistic to classify farms into rural, peri-urban and urban systems in the highlands of Ethiopia.

\begin{tabular}{cccccccccc}
\hline & \multicolumn{4}{c}{ West Shoa } & \multicolumn{4}{c}{ West Gojam } \\
\cline { 2 - 8 } & Rural & Peri- & Urban & $P^{l}$ & Rural & Peri- & Urban & $P^{l}$ \\
\hline Number of local animals & 0.405 & 0.552 & 0.315 & 0.002 & 0.470 & 0.501 & 0.745 & 0.000 \\
Number of low grade crossbreds & 1.018 & 0.382 & 0.437 & 0.000 & & & & \\
Number of medium grade crossbreds & 0.533 & 0.943 & 0.799 & 0.000 & & & & \\
Number of high grade crossbreds & 0.429 & 0.553 & 0.617 & 0.000 & 0.229 & 0.268 & 0.775 & 0.000 \\
\hline
\end{tabular}

${ }^{1}$ Significance of Wilks' Lambda statistic; ${ }^{2}$ Cows, heifers and calves; ${ }^{3}$ Low, medium and high grade crossbreds: Exotic blood level of about 25\% (First cross cow backcrossed to local breed sire), 50\% (First cross between local cow and exotic sire) and $75 \%$ and above (first cross cow crossed with pure exotic sire).

Table 2. Accuracy of classification of farmers into rural, peri-urban and urban dairy farming systems based on predictor variables using discriminant analysis.

\begin{tabular}{ccccccc}
\hline & \multicolumn{3}{c}{ West Shoa } & \multicolumn{3}{c}{ West Gojam } \\
\cline { 2 - 6 } & Rural & Peri-urban & Urban & Rural & Peri-urban & Urban \\
\hline Rural & 50.8 & 23.7 & 25.4 & 53.1 & 35.8 & 11.1 \\
Peri-urban & 13.1 & 54.1 & 32.8 & 51.7 & 28.3 & 20.0 \\
Urban & 21.7 & 25.0 & 53.3 & 30.0 & 20.0 & 50.0 \\
\hline Rural & 49.2 & 25.4 & 25.4 & 43.2 & 45.7 & 11.1 \\
Peri-urban & 14.8 & 52.5 & 32.8 & 51.7 & 25.0 & 23.3 \\
Urban & 23.3 & 26.7 & 50.0 & 30.0 & 20.0 & 50.0 \\
\hline
\end{tabular}

\subsection{Herd Genetic Structure}

The average herd size for each genotype was calculated considering only farms owning the genotype. The dairy herds were composed of both local and crossbred cows in all the three farming systems in West Shoa and West Gojam (Table 3). The average crossbred herd consisting of cows, heifers and calves was $21.9 \%$ and $19.0 \%$ in rural, $18.7 \%$ and $15.5 \%$ in peri-urban and $18.5 \%$ and $23.2 \%$ in urban systems in West Shoa and West Gojam zones, respectively. Local cows account for $26.5 \%$ to $30.5 \%$ and $18.5 \%$ to $28.4 \%$ of the total herd in West Shoa and Gojam, respectively. In West Shoa, the crossbred herd is mainly composed of low grade crosses in rural and high grade crosses in peri-urban/urban systems, accounting for $29.7 \%$ and $29.9 \%-33.0 \%$ of the herds, respectively. In West Gojam, medium (33.7\%), low grade (29.0\%) and high grade (33.6\%) crossbreds were the dominant crossbred animals in rural, peri-urban and urban systems.

Regardless of the dairy farming systems and geographic regions, most farmers in both West Shoa and Gojam kept local cows (Table 3). However, there were some variations across systems. Proportion of farmers who owned at least one local animal ranged from $42 \%$ in the urban system in West Gojam to $80 \%$ in peri-urban system in West Shoa. The high grade animals were kept by most of the farmers in urban areas in West Shoa. Fewer farmers (13\% - 25\%) kept low grade 
Table 3. Herd genetic composition and proportions of farmers keeping different genotypes of cows in rural, peri-urban and urban dairy farming systems in the wet highlands of Ethiopia.

\begin{tabular}{ccccc}
\hline & \multicolumn{2}{c}{ Average herd size } & \multicolumn{2}{c}{ Proportion of farms keeping: } \\
\cline { 2 - 5 } Rural system & West Shoa & West Gojam & West Shoa & West Gojam \\
\cline { 2 - 5 } Local animals & 5.8 & 4.6 & 0.73 & 0.56 \\
Low grade crosses & 6.5 & 4.0 & 0.34 & 0.37 \\
Medium grade crosses & 4.2 & 6.4 & 0.56 & 0.43 \\
High grade crosses & 5.4 & 4.0 & 0.53 & 0.32 \\
Peri-urban system & & & & \\
Local animals & 5.7 & 4.4 & 0.80 & 0.49 \\
Low grade crosses & 2.6 & 4.5 & 0.13 & 0.25 \\
Medium grade crosses & 4.8 & 3.2 & 0.77 & 0.49 \\
High grade crosses & 5.6 & 3.4 & 0.74 & 0.44 \\
Urban system & & & & \\
Local animals & 5.1 & 4.3 & 0.57 & 0.42 \\
Low grade crosses & 2.1 & 4.6 & 0.13 & 0.21 \\
Medium grade crosses & 5.2 & 6.5 & 0.55 & 0.26 \\
High grade crosses & 6.1 & 7.8 & 0.77 & 0.33 \\
\hline
\end{tabular}

crosses in peri-urban and urban systems than in rural system (34\% - 37\%). Rural farmers also kept more medium-high grade animals than they did low grade crosses.

Using a multinomial logistic regression analysis (Table 4), it was found that rural and peri-urban farmers in West Shoa owned $1.26(P=<0.1)$ to $1.45(P<$ $0.001)$ times more number of local dairy animals than the urban farmers. However, in West Shoa, urban farmers kept more local cows than rural farmers did. Rural farmers also kept significantly more number of low grade crossbred cows $(\mathrm{P}<0.05$; odds ratio $=2.35)$ and fewer medium $(P<0.01)$ and high grade $(\mathrm{P}=$ $0.06)$ crossbred dairy animals than urban farmers. In West Gojam, both rural and peri-urban farmers owned significantly $(P<0.05)$ fewer medium and high grade crossbred animals than urban farmers. However, the differences in crossbred herd genetic composition between the peri-urban and urban systems were not statistically significant in West Shoa. Similarly, the number of local and low grade crossbreds were statistically equal $(P>0.05)$ in peri-urban and urban systems in West Gojam.

\subsection{Trends in Herd Genetic Structure}

In the rural system, comparison of the proportions of different genotypes of crossbreds over cow, heifer and calf generations (Figure 1) showed that the proportion of high grade heifers (0.19) and calves (0.24) declined compared to the proportion of high grades achieved in the breeding cow herd (0.27). On the 
Table 4. Likelihood of keeping different genotypes of crossbred and local cows in rural and peri-urban dairy farming systems in comparison to urban system in the highlands of Ethiopia.

\begin{tabular}{|c|c|c|c|c|c|}
\hline & Genotypes & $\begin{array}{c}\text { Parameters } \\
\text { (B) }\end{array}$ & $\begin{array}{c}\text { Standard } \\
\text { error }\end{array}$ & $\begin{array}{c}\text { Significance } \\
(P)\end{array}$ & $\begin{array}{c}\operatorname{Exp}(\mathrm{B}) \\
\text { (Odds ratio) }\end{array}$ \\
\hline \multicolumn{6}{|l|}{ West Shoa } \\
\hline \multirow[t]{4}{*}{ Rural } & Local & 0.234 & 0.139 & 0.093 & 1.263 \\
\hline & $\begin{array}{l}\text { Low grade } \\
\text { crosses }\end{array}$ & 0.853 & 0.427 & 0.046 & 2.347 \\
\hline & Medium grade & -0.652 & 0.231 & 0.005 & 0.521 \\
\hline & High grade & -0.293 & 0.156 & 0.060 & 0.746 \\
\hline \multirow[t]{4}{*}{ Peri-urban } & Local & 0.370 & 0.132 & 0.005 & 1.448 \\
\hline & Low grade & -0.039 & 0.505 & 0.938 & 0.962 \\
\hline & Medium grade & 0.098 & 0.176 & 0.579 & 1.103 \\
\hline & High grade & -0.098 & .140 & .483 & .907 \\
\hline \multicolumn{6}{|l|}{ West Gojam } \\
\hline \multirow[t]{4}{*}{ Rural } & Local & -0.678 & 0.246 & 0.006 & 0.507 \\
\hline & Low grade & -0.030 & 0.312 & 0.923 & 0.970 \\
\hline & Medium grade & -0.435 & 0.219 & 0.047 & 0.647 \\
\hline & High grade & -0.473 & 0.199 & 0.018 & 0.623 \\
\hline \multirow[t]{4}{*}{ Peri-urban } & Local & -0.285 & 0.251 & 0.257 & 0.752 \\
\hline & Low grade & -0.403 & 0.371 & 0.277 & 0.668 \\
\hline & Medium grade & -0.508 & 0.239 & 0.034 & 0.602 \\
\hline & High grade & -0.696 & 0.260 & 0.007 & 0.498 \\
\hline
\end{tabular}

*The reference category was "Urban system".

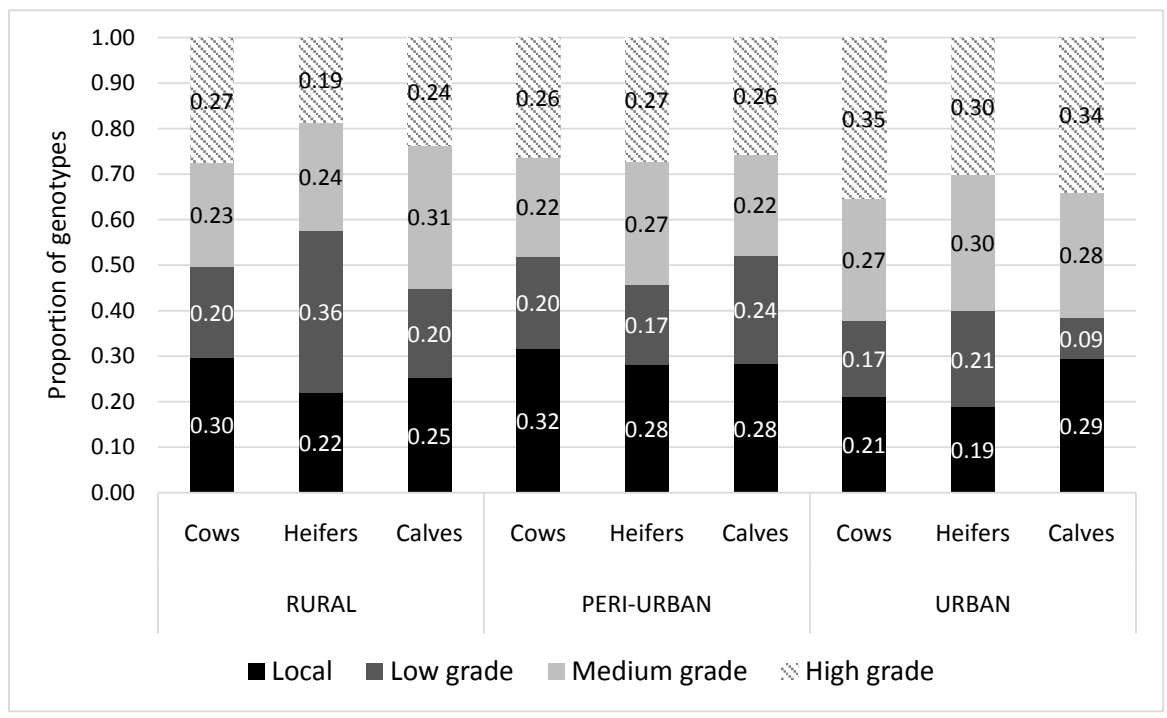

Figure 1. Proportions of local and crossbred genotypes (low, medium and high grade crosses) showing the trends in herd genetic composition over generations in West Gojjam and West Shoa zones in Ethiopia. 
contrary, the proportion of low grade and medium grade crosses increased in the heifer and calf generations, respectively. In urban system, the proportion of the high grade crosses remained fairly constant between the cow and calf/heifer generations, and the proportions of low grade crosses declined in the calf generation from 0.17 to 0.09 . The proportions seemed to remain constant across generations in the peri-urban system.

\subsection{Determinants of Herd Genetic Structure}

Access to services (breeding and extension services) and land resources and household socio-economic characteristics were evaluated for their influence on the adoption of crossbred dairy herd within each of the three dairy farming systems (Table 5). Access to breeding services, land holding and availability of rented land or the capacity to rent land, and gender of household head influenced adoption of crossbred dairy herd. The influence of these factors varied across systems. Farmers who had a better access to AI services were 1.9 times and 2.3 times more likely to own more crossbred animals than those who had less or no access in rural and urban area, respectively. The proportion of farmers who had access to AI service in rural, peri-urban and urban systems was respectively $75.5 \%, 90.9 \%$ and $84 \%$. Farmers who did not own crossbred bulls were more likely to own less number of crossbred animals in rural $(\mathrm{P}=0.000$; odds ratio $=0.596)$ and urban areas $(\mathrm{P}=0.005$; odds ratio $=0.614)$. Farmers who owned crossbred bulls were $18.6 \%, 20.7 \%$ and $7 \%$ in rural, peri-urban and urban

Table 5. Within production system determinants of crossbred herd adoption by smallholder farmers in West Shoa and West Gojam zones, Ethiopia.

\begin{tabular}{|c|c|c|c|c|c|c|c|c|c|}
\hline & \multicolumn{3}{|l|}{ Rural } & \multicolumn{3}{|c|}{ Peri-urban } & \multicolumn{3}{|l|}{ Urban } \\
\hline & $B$ & Sig. & $\operatorname{Exp}(B)^{1}$ & $B$ & Sig. & $\operatorname{Exp}(B)$ & $B$ & Sig. & $\operatorname{Exp}(B)$ \\
\hline Land for grazing/hay making (ha) & 0.214 & 0.004 & 1.238 & 0.133 & 0.117 & 1.142 & -0.144 & 0.109 & 0.866 \\
\hline Land for crop production (ha) & -0.093 & 0.042 & 0.911 & 0.098 & 0.069 & 1.103 & 0.110 & 0.014 & 1.116 \\
\hline Land rented (ha) & 0.113 & 0.170 & 1.120 & 0.280 & 0.003 & 1.323 & 0.012 & 0.913 & 1.012 \\
\hline Household size & 0.010 & 0.679 & 1.010 & -0.042 & 0.156 & 0.959 & -0.014 & 0.523 & 0.986 \\
\hline Gender (Female) & 0.057 & 0.747 & 1.058 & -0.171 & 0.170 & 0.843 & -0.291 & 0.036 & 0.748 \\
\hline Gender (Male) & $0^{\mathrm{b}}$ & & & & & & & & \\
\hline Age of household head ( 25 - 35 years) & 0.010 & 0.944 & 1.010 & -0.233 & 0.194 & 0.792 & -.0312 & 0.085 & 0.732 \\
\hline Age of household head ( $36-45$ years) & -0.202 & 0.072 & 0.817 & -0.014 & 0.899 & 0.986 & 0.086 & 0.402 & 1.090 \\
\hline Age of household head (46 - 60 years) & $0^{\mathrm{b}}$ & & & & & & & & \\
\hline Access to breeding service (AI) & 0.627 & 0.000 & 1.873 & 0.182 & 0.353 & 1.199 & 0.830 & 0.000 & 2.293 \\
\hline Access to breeding service (Bull) & $0^{\mathrm{b}}$ & & & & & & & & \\
\hline Ownership of crossbred bull (No) & -0.518 & 0.000 & 0.596 & -0.208 & 0.086 & 0.812 & -0.488 & 0.005 & 0.614 \\
\hline Ownership of crossbred bull (Yes) & $0^{\mathrm{b}}$ & & & & & & & & \\
\hline Access to extension service (No) & 0.068 & 0.597 & 1.070 & 0.336 & 0.001 & 1.400 & 0.149 & 0.200 & 1.161 \\
\hline Access to extension service (Yes) & $0^{\mathrm{b}}$ & & & & & & & & \\
\hline
\end{tabular}

${ }^{b}$ This parameter is set to zero because it is the reference category. ${ }^{1}$ Odds ratio. 
systems, whereas those who owned local bulls were respectively $20.7 \%, 33.1 \%$ and $22 \%$. Unexpectedly farmers who had no or less access to extension services were more likely to own more number of crossbreds.

Availability of private grazing or hay making plot significantly determined ownership of crossbred herd $(\mathrm{P}<0.05)$ in the rural system. The result indicated that an increase in one ha of grazing/hay land would result in an increase of 0.21 heads of crossbreds in the herd. Rural households who had larger crop plots were found to own less number of crossbred animals, whereas the reverse was true in urban areas. The availability of rented land or the capacity to rent land is positive influenced ownership of crossbred cattle in peri-urban areas. Mean crop, private grazing/hay and rented land respectively were 1.5, 0.5 and 0.3 in rural, 1.5, 0.5 and 0.1 in peri-urban and 1.2, 0.4 and 0.1 ha in urban systems. Another significant determinant was gender of household heads which had influence on adoption of crossbred herds in urban areas.

\section{Discussion}

One of the major distinctions between smallholder dairy farming systems in the highlands of Ethiopia is the type of breeds and genotypes kept by farmers. The genetic structure described in the current study is in general agreement with previous results in Ethiopia in that crossbred herds are more predominant in the urban and peri-urban systems than in the rural system [2] [4] and elsewhere in Africa where use of AI breeding service and herd genetic composition were found to be significant discriminating factors among peri-urban farmers in Mali [6]. The urban/peri-urban systems have been commonly and grossly characterized as crossbred-based systems in Ethiopia [2] [4], crossbred cows accounting for up to $97.5 \%$ of the herds [9]. Such characterization could represent the urban/peri-urban systems in and around big federal and regional cities and major milk sheds. However, our results which were based on rigorous statistical analysis indicated that the characterization of the systems, particularly peri-urban/ urban systems, needs qualification. It was found in the current study that merely $38 \%-50 \%$ of urban/peri-urban farms conformed to the characteristics of these systems, namely breeding for high/medium grade crossbreds. This result is in agreement with a previous report for urban systems in regional towns (which were similar to the regional towns in the current study) where the proportion of crossbred cows accounted for only $26 \%-40 \%$ of the total herd [3]. The current results thus call for the qualification of the classification and/or the characterization of the smallholder dairy systems in and around the big cities and regional towns to inform research and development policies, strategies and interventions.

A major distinction between the three systems observed in this study was that rural farmers are more likely to keep low grade crosses with exotic blood levels of around $25 \%$ and less likely to keep high grade crossbred cows with exotic blood levels of $75 \%$ and above than urban/peri-urban farmers. This is in agreement with [2] and [4] observations that medium to high grade crossbred cows are kept in urban systems in Ethiopia. The exotic inheritance level in village cat- 
the herds could be due to farmers' conscious preferences for the various exotic blood levels or lack of awareness and/or access to breeding services. Farmers' highest preference ranking in rural and peri-urban/urban areas respectively were for $<50 \%$ and $50 \%-75 \%$ exotic blood levels in West Shoa [10] and 50\% - 75\% exotic blood level was preferred elsewhere in the highlands of Ethiopia [11] The choice of breeds and genotypes of crossbreds for smallholder systems in Ethiopia need to consider the dairy value chain. Where the value chain is not functioning well, such as in the rural areas, where access to inputs and services and profitable markets for fresh milk is limited, the indigenous and low grade crossbred cows could be the best choice. However, it could be more likely that the low grade crosses with $25 \%$ exotic blood in rural areas in the current study are a result of lack of access to AI breeding services where farmers are forced to backcross $50 \%$ exotic crossbred cows to local bulls. This argument is supported by the higher number of local bulls in rural areas ( 0.73 bulls per household) compared to periurban (0.69) and urban areas (0.32) in West Shoa where low grade crosses are higher in rural areas, whereas in West Gojam where low grade crosses are higher in Peri-urban and urban areas, the average number of local bulls were $0.12,0.28$ and 0.23 in rural, peri-urban and urban systems. A similar pattern has been reported elsewhere in Ethiopia; for instance most of the farmers in Lay Armacho (95\%), Debark (95\%) and Gondar Zuria (75\%) districts did not keep the initial proportion of exotic genes in their herd constant [11] Backcrossing of firstcrosses has been found to significantly affect milk production performance where daily milk yield was reduced from 6.2 in $50 \%$ first crosses to 5.6 liters in F2 backcrosses [12]. Maintaining the desired exotic blood level in village herds has proved difficult resulting in genetically admixed village population in Ethiopia due to inefficient AI system and absence of controlled breeding in village herds due to communal grazing systems, particularly in rural areas. Dispersed settlement in rural Ethiopia coupled poor infrastructure including roads, transportation and telecommunication is one of the reasons for the low efficiency of AI service. Efficient delivery of AI service to individual farmers as and when each cow shows oestrous signs is impracticable. The AI service and delivery of improved dairy genetics to smallholders could be improved by introducing hormonal oestrus synchronization and mass artificial insemination [13]. The effort to improve the dairy cattle crossbreeding/AI program through hormonal oestrus synchronization has been below expectation [14] due to factors related to inefficient AI service, poor infrastructure and farmers' awareness, although the synchronization technology has been successfully demonstrated through action research [10].

An important characteristic of the urban and peri-urban dairy farming systems in and around the regional towns identified in the current study is that local dairy cows are numerically equally important in all the three systems, though this varied between the geographic regions studied. On the contrary, studies on the characterization of the smallholder dairy systems have considered keeping local cows as characteristics of the rural system and not of the urban/peri-urban 
systems. Local breeds have received little attention from the national dairy cattle genetic improvement programs which has been taken virtually as synonymous to crossbreeding programs. Yet after decades of implementation of the national Holstein Friesian dairy cattle crossbreeding program, the proportion of the crossbred animals has not exceeded $1 \%$ of the national herd in Ethiopia [15]. Thus the local dairy breeds are still prominent in the dairy genetics landscape of developing countries and thence continue to be an important resource in genetic improvement and dairy development strategies in all dairy farming systems excluding the systems located in and around the big cities. Besides their numerical importance, the indigenous cattle breeds are generally characterized as multipurpose animals, can be managed in low input production system and are adapted to marginal environments. However, the current data on herd genetic structure with admixture of different breeds and genotypes including in the rural system which is believed to be the sanctuary for the indigenous genetic resources could be an indication of absence of well-planned and designed crossbreeding program, which could lead to indiscriminate crossing and threat to the adapted indigenous resources. The threat to the adapted indigenous resources is however more pronounced in the peri-urban/urban system according to the current data and elsewhere in Africa where, for instance, the proportion of crossbreds reached close to $40 \%$ in 2015 from $9 \%$ in 2004 in peri-urban system in Bamako [6]. However, the local breeds are inherently low milk producers as they have been naturally selected for adaptive traits and not functional traits [3]. Selective breeding could be the best option to improve the genetic merits of the indigenous breeds. However, to implement effective selection programs in village herds, there are constraints relating to the characteristics of smallholder village herd structure, infrastructures and attitudes of the public and private sectors towards selective breeding programs. The focus on the local genetic resources could vary across geographic regions. For instance in the current study local breeds are more important in West Gojjam zone than in West Sho zone which is located in the greater Addis Ababa milkshed where there is better access to breeding services and markets for fresh milk.

Of the total 360 farms surveyed in West Shoa and West Gojam zones in this study, only $50.6 \%$ and $38.7 \%$ of the farms, respectively, conformed to the typical breeding characteristics identified by the analysis model for rural, peri-urban and urban dairy farming systems. This has an important implication in the designing and introduction of appropriate dairy development interventions. This is particularly relevant to the peri-urban system where the highest misclassification was observed. Identification of determinants of herd genetic structure regardless of the influence of farming systems showed that access to breeding services and land resources were the most important factors. The low proportion of crossbred cows in existing herds in the current study sites is contrary to farmers' preferences for crossbred cows as elicited for the same study site [10] and elsewhere in the highlands of Ethiopia [11]. The major constraint to meet farmers' preferred dairy breeds and genotypes is the limitation in the AI service. The con- 
ception rate to first AI service has been reported to be as low as $27.1 \%$ [16], and the major challenge as reported by farmers is poor heat detection where AI is accessible, whereas access to reliable AI service has also been reported to be very low even in the peri-urban areas in an extensive study in the four highland regions of Ethiopia [10]. The service is neither better around Addis Ababa where dissatisfaction has been expressed by about $46.7 \%$ of farmers surveyed [17]. It has been argued [18] that utilization and improvement of the desired crossbred population can only be efficient in situations where breeding programs with well-defined breeding objectives, breeding structure and infrastructure are developed, which is often lacking at smallholder level in the tropics.

Land and herd holding are characteristic of dairy farming systems in Ethiopia. Land holding is a major factor limiting scale of production together with other factors such as access to external inputs, markets and credit services, as well as farmers' degree of market-orientation. Land shortage is particularly a major challenge for urban farmers in the current study to expand the scale of production and productivity. Land shortage is a major problem constraining dairy development elsewhere in the country, for instance in SNNP state where 100\% of both rural and urban farmers interviewed reported land shortage as number one constraint [19] and as reviewed by [4]. Land holding in the highlands of Ethiopia is generally small and comparable to the land holding in the sampled households in the current study. Average land holdings of 1.3 to 2.7 ha have been reported for the highlands of Ethiopia [20] [21] [3]. This is in contrast to the larger farm size of 8.5 ha in the lowlands of Ethiopia [22] [3]. The national average agricultural land holding and grazing/fodder production land per household is 2.5 and $0.26 \mathrm{ha}$, respectively [23]. The leverage point to increase scale of production is land, particularly for peri-urban and urban systems. It is argued that change in milk production due to herd size explains $60 \%$ of the increase, but only $20 \%$ from technology change [24].

\section{Conclusion}

This study validated the classification of smallholder dairy farming systems in the highlands of Ethiopia through rigorous statistical analysis of herd genetic structure. Herd genetic structure was found to be a significant classifying characteristics of smallholder dairy farms; high and medium grade crossbreds are more predominant in the urban and peri-urban systems, low grade crosses predominate in the rural system, and the local cows are still the dominant dairy animals not only in the rural system but also in the peri-urban and urban dairy systems despite these systems are targeted for improved dairy genetics by the national dairy cattle breeding strategy. Since reclassification of sampled farms showed that merely $38 \%$ - $50 \%$ of the farms conformed to the characteristics of their original systems, our results indicate towards the qualification of dairy farming system characterization, particularly the urban/peri-urban systems in/ around regional towns versus big cities. Secondly, considering farms within systems as a uniform unit to target development interventions may not be appro- 
priate and farm topologies and system specific determinants of farmers' breeding strategies need to be considered to design and introduce development interventions. The design needs to consider correcting the high admixture of crossbred exotic blood levels and conservation of the adapted local breeds at least in the rural areas.

\section{Acknowledgements}

The studies were financially and technically supported by Livestock and Irrigation Value Chains for Ethiopian Smallholders (LIVES) project of the International Livestock research Institute. LIVES project is financed by Global Affairs Canada (GAC).

\section{References}

[1] Ketema, H. and Tsehay, R. (1995) Dairy Production Systems in Ethiopia. Proceedings of a Workshop Entitled: Strategies for Market Orientation of Small Scale Milk Producers and Their Organizations, Morogoro, 20-24 March 1995.

[2] Tsehay, R. (2002) Small-Scale Milk Marketing and Processing in Ethiopia. Smallholder Dairy Production and Market Opportunity and Constraints: A South-South Workshop, Anand, 13-16 March 2001.

[3] Azage, T., Berhanu, G. and Dirk, H. (2013) Smallholder Dairy Production and Marketing Systems in Ethiopia: IPMS Experiences and Opportunities for Market-Oriented Development. International Livestock Research Institute (ILRI), Nairobi.

[4] Matawork, M.G. (2012) Household Dairy Production System, Marketing and Constraints in Ethiopia. Journal of Marketing and Consumer Research, 29, 46-51.

[5] Gillah, K.A., Kifaro, G.C. and Madsen, J. (2012) Urban and Peri Urban Dairy Farming in East Africa: A Review on Production Levels, Constraints and Opportunities. Livestock Research for Rural Development, 24.

[6] Toure, A., Nassim, M., Ali, K., Bakary, T., Kisito, T., Pascal, L. and Nicolas, A.M. (2015) Dairy Farms Typology and Management of Animal Genetic Resources in the Peri-Urban Zone of Bamako (Mali). Journal of Agriculture and Rural Development in the Tropics and Subtropics, 116, 37-47.

[7] Ojango, J.M.K., Wasike, C.B. and Okeyo, A.M. (2016) Dairy Production Systems and the Adoption of Genetic and Breeding Technologies in Tanzania, Kenya, India and Nicaragua. Animal Genetic Resources, 59, 81-95. https://doi.org/10.1017/S2078633616000096

[8] Shapiro, B.I., Gebru, G., Desta, S., Negassa, A., Nigussie, K., Aboset, G. and Mechal, H. (2015) Ethiopia Livestock Master Plan. International Livestock Research Institute, Nairobi.

[9] Yoseph, M., Azage, T., Alemu, Y. and Umunna, N.N. (2003) Evaluation of the General Farm Situation and Herd Structure of Dairy Herds at Various Physiological Stages in Urban and Peri-Urban Dairy Production System in the Addis Ababa milkshed. Proceedings of the 10th Annual Conference of the Ethiopian Society of Animal Production, Addis Ababa, 22-24 August 2002, 139-144.

[10] Gizaw, S., Abera, M., Muluye, M., Hoekstra, D., Gebremedhin, B. and Tegegne, A. (2016) Smallholder Dairy Farming Systems in the Highlands of Ethiopia: System-Specific Constraints and Intervention Options. International Livestock Research Institute, Nairobi. 
[11] Kluszczynska, M. (2012) Crossbreeding Strategies for Dairy Cattle: Introduction, Development and Impact on Smallholder Farmers in North Gondar, Ethiopia. MSc Thesis, University of Natural resources and Life Sciences, Viena.

[12] Demeke, S., Neser, F.W.C., Schoeman, S.J., Erasmus, G.J., Van Wyk, J.B. and Gebrewolde, A. (2012) Crossbreeding Holstein-Friesian with Ethiopian Boran Cattle in a Tropical Highland Environment: Preliminary Estimates of Additive and Heterotic effects on Milk Production Traits. South African Journal of Animal Science, 30, 32-33.

[13] Azage, T., Dirk, H., Gebremedhin, B. and Gizaw, S. (2016) History and Experiences of Hormonal Oestrus Synchronization and Mass Artificial Insemination of Cattle for Improved Genetics in Ethiopia: From Science to Development Impact. International Livestock Research Institute, Nairobi.

[14] Fantahun, T. and Admasu, Z. (2017). Evaluation of Oestrus Synchronization and Mass Artificial Insemination Service of Dairy Cattle in Mizan Aman Area, Bench Maji Zone, South West Ethiopia. International Journal of Livestock Production, 8, 1-4. https://doi.org/10.5897/IJLP2016.0338

[15] CSA (Central Statistical Agency) (2015) Agricultural Sample Survey 2014/15. Report on Livestock and Livestock Characteristics. Statistical Bulletin, 2, 578.

[16] Desalegn, G., Merga, B., Azage, T. and Kelay, B. (2009) Status of Artificial Insemination Service in Ethiopia. The 17 th Annual Conference of the Ethiopian Society of Animal Production (ESAP), Addis Ababa, 24-26 September 2009, 87-104.

[17] Kelay, B.D. (2002) Analyses of Dairy Cattle Breeding Practices in Selected Areas of Ethiopia. Ph.D. Thesis, Humboldt-Universität zu, Berlin.

[18] Kahi, A.K. (2002) Crossbreeding Systems and Appropriate Levels of Exotic Blood: Examples from Kilifi Plantations in Kenya. https://cgspace.cgiar.org/handle/10568/3578

[19] Ayza, A., Zelalem, Y. and Ajebu, N. (2013). Characterization of Milk Production Systems in and around Boditti, South Ethiopia. Livestock Research for Rural Development, 25.

[20] Asaminew, T. (2007) Production, Handling, Traditional Processing Practices and Quality of Milk in Bahir Dar Milk Shed Area, Ethiopia. MSc Thesis. Haramaya University, Haramaya.

[21] Kedija, H. (2007) Characterization of Milk Production System and Opportunity for Market Orientation: A Case Study of Mieso District, Oromia Region, Ethiopia. MSc Thesis, Haramaya University, Haramaya.

[22] Adebabay, K. (2009) Characterization of Milk Production Systems, Marketing and On-Farm Evaluation of the Effect of Feed Supplementation on Milk Yield and Milk Composition of Cows at Bure District, Ethiopia. MSc Thesis, Bahir Dar University, Bahir Dar.

[23] CSA (Central Statistical Authority) (2013) Agricultural Sample Survey 2013/14. Report on Livestock and Livestock Characteristics, Addis Ababa.

[24] Land O'Lakes (2010) The Next Stage in Dairy Development for Ethiopia: Dairy Value Chains, End Markets and Food Security. Land O'Lakes, Inc., Addis Ababa. 
Submit or recommend next manuscript to SCIRP and we will provide best service for you:

Accepting pre-submission inquiries through Email, Facebook, LinkedIn, Twitter, etc. A wide selection of journals (inclusive of 9 subjects, more than 200 journals)

Providing 24-hour high-quality service

User-friendly online submission system

Fair and swift peer-review system

Efficient typesetting and proofreading procedure

Display of the result of downloads and visits, as well as the number of cited articles Maximum dissemination of your research work

Submit your manuscript at: http://papersubmission.scirp.org/

Orcontact as@scirp.org 